V. 13 N. 1

JAN-ABR 2017

ISSN 2317-6172

Recebido: 13.10 .2014

Aprovado: 07.02.2017

Dol: http://dx.doi.org/10.1590/2317-6172201703

1 Pontifícia Universidade Católica do Paraná Curitiba - PR - Brasil

2 Universidade Estadual do Oeste do Paraná Cascavel - PR - Brasill

3 Centro Universitário Autônomo do Brasil - UniBrasil Curitiba - PR - Brasil

\section{Mecanismos jurídicos e econômicos para a transferência de tecnologia: um estudo de caso}

\author{
LEGAL AND ECONOMICAL MECHANISMS FOR TECHNOLOGY TRANSFER: A CASE STUDY \\ Marcia Carla Pereira Ribeiro', Weimar Freire da Rocha Jr. ${ }^{2}$ \\ e Vivian Amaro Czelusniak ${ }^{3}$
}

\section{Resumo}

0 trabalho analisa mecanismos para a eficiência dos negócios empresariais de transferência de tecnologia. Utiliza a ferramenta da análise econômica do direito em razão de sua adequação para estudos relacionados às modalidades negociais que se protraem no tempo, nos quais a confiança entre as partes torna-se fundamental para a manutenção das relações. 0 método de procedimento utilizado neste ensaio foi o monográfico, a técnica de pesquisa foi a bibliográfica e o estudo de caso, de transferência de tecnologia em biogás. Como resultados, vislumbrou-se que a cooperação é um instrumento para que os negócios empresariais e os contratos empresariais de transferência de tecnologia sejam mais efetivos, na medida em que pode diminuir a probabilidade de demandas judiciais referentes a estes contratos, bem como é instrumento de estabilização, promovendo a manutenção dos negócios por um maior período de tempo.

\section{Palavras-chave}

Cooperação; negócios e contratos; transferência de tecnologia; análise econômica; biogás.

\begin{abstract}
This paper analyzes mechanisms for the efficiency of technology transfer transactions. It adopts the economic analysis of law as a tool, due to its adequacy on studies about agreements that normally rely on time and in which confidence between the parties becomes fundamental to maintain the relationships. The procedural method used in this paper was the monographic, the technique of research was the bibliographical and the case study was about biogas technology transfer. As for results, it was envisioned that the cooperation is a tool for the business and the corporate contracts of transfer of technology become more effective, to the extent that it can decrease the likelihood of litigation relating to these contracts, as well as it is a stabilisation instrument, promoting the maintenance of the business for a longer period of time.
\end{abstract}

\section{Keywords}

Cooperation; business agreements; technology transfer; economic analysis; bio-gas. 


\section{INTRODUÇÃO}

A região oeste do Paraná tem sua economia assentada no agronegócio, no qual se inclui o sistema agroindustrial da carne suína. Em 2001, o sistema agroindustrial apresentou uma produção de aproximadamente 2,7 milhões de toneladas e, em 2015, este valor cresceu aproximadamente 29,5\% e passou para 3,5 milhões de toneladas (OECD/FAO, 2015).

Este volume de produção é acompanhado de uma série de benefícios, como a geração de renda, emprego e tributos para os municípios nos quais o sistema agroindustrial está estabelecido. Por outro lado, surgiram desafios na área ambiental, dentre eles, os problemas da carga poluidora dos animais. Esta externalidade pode ser amenizada pelo uso de tecnologia que transforma os dejetos em biogás, uma fonte energética que pode ser aproveitada nas regiões em que se criam suínos com amplo potencial de redução do passivo ambiental decorrente da atividade. Para o bom funcionamento do processo de produção de biogás, é necessária a sua purificação para transformá-lo em gás metano, que, além de possuir inúmeras aplicações econômicas, pode servir para a redução de impacto no efeito estufa.

Diante da possibilidade de conjugação do interesse comercial, na produção e venda de equipamentos, do interesse acadêmico no desenvolvimento de pesquisas no âmbito das universidades e das necessidades locais, este estudo optou pela escolha e análise de um contrato específico que reúne universidade e empresa no processo de desenvolvimento, fabricação e venda de equipamentos de biogás. A escolha específica do contrato decorreu, ainda, da percepção de que se trata de um modelo bastante usual no estabelecimento da relação entre universidade/empresa no campo da produção de pesquisa e colocação no mercado de produtos.

O contrato, elemento formal de ligação entre as partes, pode ser entendido como uma possível estrutura de governança que visa a reduzir os custos de transação que seriam decorrentes da opção pela integração vertical, ou pela simples busca inespecífica do produto no mercado.

Porém, quando aplicado a questões ligadas à comercialização de tecnologia, os contratos merecem uma especial atenção porque ostentam um grau de complexidade maior, e os erros ou acertos no seu conteúdo terão um potencial de impacto bastante relevante para a conclusão dos objetivos do contrato e para o desenvolvimento tecnológico a que está atrelado.

Em que pese a possibilidade de aprimoramento, o contrato de transferência de tecnologia não terá plenas condições de acertamento de todos os fatores relacionados à transação, até mesmo porque sendo anterior à colocação do produto no mercado, não há possibilidade de avaliação do real potencial de comercialização do bem. Ao mesmo tempo, para que a pesquisa teórica e a produção empresarial sejam compatibilizados é necessário que o conhecimento seja repassado de uma parte contratual à outra, o que torna a confiança entre as partes um elemento essencial que pode evitar atitudes defensivas e evasivas que possam influir negativamente na contratação e nos seus resultados. 
O problema abarcado neste artigo consiste em identificar os principais gargalos técnicos e informacionais cujos efeitos negativos possam ser ultrapassados por intermédio da elaboração de cláusulas de um Contrato de Transferência de Tecnologia (CTT). Buscar-se-á apresentar as principais motivações e restrições que estimulam a cooperação entre as partes como fator de efetivação e manutenção do negócio. Será apresentada, ainda, uma análise relativamente ao teor do contrato-modelo estudado e sua potencialidade de gerar litígios, assim como aquilatada a existência de cláusulas auxiliares à conduta cooperativa e a importância do ambiente cooperativo.

A justificativa para o desenvolvimento deste estudo está na possibilidade de apresentar elementos que no futuro facilitem a cooperação entre as partes e contribuam com a melhor aproximação entre as universidades e as empresas em atitudes que promovam o desenvolvimento, amparadas pela formulação de contratos.

Além das considerações de ordem teórica, o trabalho apresenta um estudo de caso de um modelo contratual de transferência tecnológica entre uma Instituição Pública de Ensino e Pesquisa e uma empresa privada da área metal-mecânica, ambos da região oeste do Estado do Paraná, além de também apresentar os resultados de entrevistas realizadas pelos pesquisadores perante os signatários do modelo contratual analisado - o pesquisador, representante da universidade, e o empresário, representante legal da empresa - a fim de confirmar o nível de conhecimento quanto ao teor do contrato e a importância de determinados fatores externos na escolha para contratação.

A técnica usada para a obtenção de dados foi a pesquisa documental e entrevistas, e a metodologia utilizada vem descrita no $3^{\circ}$ tópico deste artigo.

Neste sentido, o estudo foi segmentado em seis partes, cuja introdução apresenta a visão panorâmica, o problema, o objetivo e alguns aspectos da metodologia utilizada. Na segunda parte foi desenvolvida a revisão de literatura focada no contrato, na cooperação e na Nova Economia Institucional. A seguir, é apresentado um panorama sobre os contratos de transferência de tecnologia, para, na quarta parte, ser incorporada a metodologia adotada para o estudo de caso. Posteriormente, foi apresentado o contrato de transferência tecnológica escolhido, assim como uma análise crítica de algumas de suas cláusulas, para, em seguida, ser apresentada a consolidação do resultado das entrevistas para finalizar-se com a conclusão.

\section{CONTRATO, COOPERAÇÃO E NOVA ECONOMIA INSTITUCIONAL}

Sob a ótica da colaboração, para que seja estabelecida uma relação de confiança entre as partes num contrato, são necessários estímulos para a cooperação, com o intuito de que haja a continuidade das relações e, consequentemente, a preservação da relação negocial para o futuro. A partir do pensamento desenvolvido por Coase (1960), a solução mais eficiente para a economia, desde que bem definidos os direitos de propriedade, seria alcançada 
a partir da colaboração mútua das partes da relação jurídica para a busca de uma resolução de controvérsias dotada de maior potencialidade de redução de custos de transação, tomados como custos relacionados aos processos de trocas ou comércio.

O princípio da cooperação não aparece de forma isolada, e, no âmbito do Direito brasileiro, pode ser considerado como estando relacionado ao princípio da solidariedade, de modo que em "todas as atividades desempenhadas, seja nos atos sem relevância para o direito, seja no cumprimento de relações obrigacionais, existe uma imposição de cooperação de não abusar de outrem, de se exercer os direitos de acordo com sua finalidade social" (NANNI, 1999, p. 297). Ou, ainda, associado ao princípio da boa-fé, tomado como princípio geral, o qual, conjuntamente a outros consagrados no Código Civil ganharam em importância como instrumento de atualização do direito e até mesmo como ferramenta de ativismo do Poder Judiciário (GALLO, 2009).

Entretanto, mesmo quando as partes se dispõem a cooperar, há imperfeições que atingem a negociação. Uma delas reside na impossibilidade de redação de contratos que disciplinem de forma ótima todas as condições relativas ao contrato de maneira a contemplar plenamente o interesse individual de cada uma das partes. E, quanto mais dilatado no tempo o contrato, maior a inviabilidade de estabelecimento de um contrato completo.

O Direito imposto pelo Estado pode ser pensado como uma alternativa às soluções privadas perfeitas. Como o direito imposto contempla a aplicação das leis e também o cumprimento dos contratos, influenciará as relações mercadológicas e econômicas (COOTER; ULEN, 2010).

Por outro lado, o contrato pressupõe colaboração das partes, quer seja quando acordam por firmar o contrato, adequando suas expectativas, quer seja quando agem em conformidade com o pactuado. Há estratégias que, uma vez incorporadas aos contratos, podem induzir à cooperação. Axelrod (2010), com base em experimento empírico, afirmou que a cooperação pode derivar de estratégias formuladas pela parte e em seu benefício. O autor analisa alguns fatores que estimulam a cooperação entre as partes e que podem ser incorporados aos contratos. Alguns serão revisados nesse texto.

Segundo Axelrod (2010), haverá uma cooperação mútua no decorrer do contrato se as partes vislumbrarem que o futuro da relação é mais importante do que o presente. Essa conclusão decorre do fato de que, considerando-se o contrato como um jogo, cada um dos jogadores pode querer usar uma ameaça implícita de retaliações contra o outro e, assim, a relação jurídica só perdurará pelo período suficiente para que este jogador torne a ameaça realmente efetiva. Para o autor, essa situação contribui para a elucidação do primeiro dos requisitos para o estímulo à cooperação entre as partes: aumentar a expectativa das partes em relação ao futuro, o que pode ser garantido de duas maneiras: por meio de intercâmbios mais duráveis ou mais frequentes.

Outro modo de se fazer com que esses intercâmbios sejam mais frequentes, a partir da visão de Axelrod (2010), é quebrar os problemas em partes menores. Essa estratégia 
permitiria que as partes pudessem realizar muitos movimentos, entretanto, relativamente pequenos, ao invés de grandes movimentos. Assim, decompondo-se as interações, promove-se uma estabilidade no contrato e torna-se os ganhos de uma possível traição muito menos importantes em relação aos potenciais ganhos a partir de uma cooperação mútua em movimentos futuros.

Para Axelrod (2010), ensinar para as pessoas a reciprocidade também pode fomentar a cooperação. Nesse caso, um jogador, para estimular novas relações jurídicas, necessita tratar o outro jogador da mesma maneira como o outro o tratou. Para tanto é necessário que os jogadores lembrem das interações anteriores, com o escopo de rememorar as características que foram importantes naquelas interações.

Relativamente aos CTTs e suas incertezas e delimitações, será importante que contenham cláusulas que favoreçam futuras renegociações. Em casos inesperados, que produzam alterações no andamento ordinário do contrato, uma boa relação de cooperação entre as partes pode levar a uma fácil resolução privada, sem a necessidade de intervenção do Poder Judiciário, por exemplo (CZELUSNIAK; RIBEIRO, 2013).

Podem também ser criadas cláusulas contratuais que induzam a determinada conduta, como, por exemplo, a precisa determinação do conteúdo que a parte que transfere a tecnologia se obriga a repassar ao outro contratante, sob pena de multas desencorajadoras. Quando a pena ou dever de pagamento de uma indenização for superior ao valor a ser obtido em um eventual descumprimento, a parte contratante sentir-se-á mais estimulada a cumprir com a sua obrigação (CZELUSNIAK; RIBEIRO, 2013).

Quando as partes pretendem realizar um negócio, normalmente têm parte dos conhecimentos sobre o objeto da negociação, muitas vezes, possuem informações discrepantes e incompletas em relação a este objeto. Essa situação é conhecida como assimetria informacional (RIBEIRO; GALESKI JUNIOR, 2016). Ela será negativa quando dificultar as contratações. Entretanto, poderá ser motivo para a realização de um contrato, por exemplo, quando uma parte necessita de informação que a outra possui e, em decorrência disso, firma um contrato com o objetivo de obter informações (RIBEIRO; GALESKI JUNIOR, 2016). Ressalta-se que esta é a situação ocorrida nos CTTs.

Por outro lado, não há como abstrair os negócios do ambiente institucional em que são projetados e para o qual projetam seus efeitos. Segundo North (1994), as instituições são consideradas como as regras do jogo sob as quais os negócios se operam. Essas regras podem ser tanto de índole formal (como as leis), quanto informal (convenções, normas de comportamento).

O contrato tem um papel importante na Nova Economia Institucional (NEI), pois existem vários tipos de estrutura de governança e cada uma delas detém uma forma específica de arranjo entre os agentes, na busca pela minimização dos custos de transação (WILLIAMSON, 2002). Em algumas circunstâncias, o contrato pode se apresentar como uma estrutura de governança mais ajustada aos atributos da transação que são pretendidos - quando, por exemplo, comparado com uma estrutura de mercado ou de integração vertical (firm) -, o 
que proporciona mais eficiência ao sistema, já que sua função é a de facilitar trocas de produtos e/ou serviços entre os agentes (WILLIAMSON, 2002). No campo da CTTs, dada a especificidade do objeto, corrobora-se a utilização do contrato (ROCHA JR.; BITTENCOURT; RIBEIRO, 2013).

O contrato também possui a característica de ser uma ferramenta para a circulação de mercadorias e/ou serviços, direcionando o fluxo desses bens para as partes que estão mais interessadas em adquiri-los, de forma que há a liberdade da escolha entre as partes, com o objetivo de selecionar qual será o agente econômico a ser contratado, e a liberdade da negociação dos termos, no instante em que se pactuarem esses interesses (ARAÚJO, 2007). Zylbersztajn e Sztajn (2005) destacam como aspectos relacionados aos contratos a incompletude, os custos e a duração.

A incompletude contratual ocorre pois os agentes não conseguem prever todas as situações futuras que podem ocorrer na relação jurídica. Associa-se aos pressupostos de cunho comportamental do agente econômico, quais sejam: a racionalidade limitada e oportunismo (WILLIAMSON, 2002). Além dessas variáveis, podem ser citadas outras, como: questões socioeconômicas, demográficas, tecnológicas e governamentais, que fazem com que haja constante incerteza na contratação, motivando o oportunismo (ROCHA JR.; BITTENCOURT; RIBEIRO, 2013). Torna "os contratos complexos e conduz à criação de salvaguardas ex ante (na tentativa de coibir quebra contratuais) e ex post, após a verificação de uma falha contratual. A variável tempo é outro elemento relevante que também influenciará os contratos" (ROCHA JR.; BITTENCOURT; RIBEIRO, 2013, p. 989-990).

Tirole (2009) destaca que o contrato incompleto e uma limitada heurística cognitiva podem desencadear ineficiências, pois os indivíduos muitas vezes não recebem, dentro das organizações, incentivos para pensar na elaboração de um contrato perfeito (na medida do possível), tendo em vista caminhos de dependência dessa organização, estratégias com o fim de permanecer na organização e em razão do incentivo propriamente dito. Contudo, McDonald et al. (2004) assinalam alterações nas estruturas de governança, ocorridas a partir da década de 1960, com a consolidação do contrato como ferramenta para a redução de riscos, por permitir que as partes se ajustem às necessidades comuns e criem um ambiente favorável à redução dos custos de transação.

De um lado há o interesse do agente em manter sua posição na empresa - (caminho de dependência) que induz a estratégias de elaboração de contratos incompletos e se afasta da percepção do contrato como um elemento redutor dos custos de transação. De outro, a prática e as pesquisas consolidaram o contrato como estrutura de governança estável e vocacionada a ser cumprida, apta a orientar a conduta dos agentes por meio da normatização de suas condutas (ROCHA JR.; BITTENCOURT; RIBEIRO, 2013).

O contrato reduz as possibilidades de seleção do comportamento, com uma potencial atenuação dos riscos de inadimplemento. Por outro lado, o aperfeiçoamento das previsões contratuais, decorrência do maior acesso à informação, colabora para que um maior 
número de comportamentos seja disciplinado no contrato (ROCHA JR.; BITTENCOURT; RIBEIRO, 2013).

\section{Contratos de TransferênCia de TeCnOlogia}

A transferência de tecnologia é um negócio jurídico complexo, que pode se dar por meio de vários tipos contratuais. Em um sentido amplo, os Atos Normativos (ATs) do Instituto Nacional da Propriedade Industrial (INPI) informam alguns exemplos que abrangem: contratos de cessão e de licenciamento de marcas e patentes, contratos de fornecimento de tecnologia não patenteada, contratos de assistência técnica e serviços técnicos, contratos de pesquisa e contratos de franquia (CZELUSNIAK; RIBEIRO, 2013).

O objeto da transferência de tecnologia é a transmissão de bens intelectuais (criações, segredos e software) que podem estar protegidos por institutos de Propriedade Intelectual (PI), como as patentes, ou podem ser conhecimentos técnicos não protegidos, mas que se encontrem em sigilo e sejam passível de apropriação econômica (ASSAFIM, 2005). Corrêa (2005, p. 96) considera a transferência de tecnologia apenas como a transmissão dos conhecimentos por uma parte (transmissor) e a assimilação desses conhecimentos pela outra (receptor), não relacionando o conceito com os bens imateriais, como ocorre nos ATs do INPI.

Em alguns tipos contratuais, como nos contratos de cessão ou de licenciamento de patentes, os conhecimentos estão descritos num documento que é acessível a todas as pessoas, pois se encontra depositado no INPI (registro público), a não ser que haja falhas no documento (de ordem proposital ou não) (CZELUSNIAK; RIBEIRO, 2013). No caso de transferências de tecnologia não contidas em documentos de registro público (know how), percebe-se a necessidade da descrição da tecnologia dentro do contrato, de modo tal que possa ser totalmente assimilada pela parte receptora. Nesta hipótese, podem ocorrer situações de ação oportunista do transmissor, o qual poderá omitir alguma informação essencial (PRADO, 1997; CZELUSNIAK; RIBEIRO, 2013).

Porém, em razão da assimetria informacional, é possível que o receptor da tecnologia não consiga perceber se possui todas as informações indispensáveis à reprodução da tecnologia, ou descubra somente após a contratação, depois de já ter investido pesadamente na aquisição da tecnologia (CZELUSNIAK; RIBEIRO, 2013), o que atesta a relevância de se considerar a assimetria informacional como um custo de transação a ser ponderado.

Segundo Czelusniak e Ribeiro (2013), outro fator que aumenta o custo da transferência de tecnologia são as dificuldades do Poder Judiciário em resolver demandas judiciais decorrentes dos contratos. O que se percebe é que muitas vezes as autoridades envolvidas na resolução dos conflitos não possuem conhecimentos tecnológico e mercadológico necessários para a resolução do conflito com presteza, o que, além de aumentar os custos, amplia também o risco nas demandas. Além desse, outro fator relacionado aos custos está na remuneração da atuação de peritos especializados. 
Os impactos dessas dificuldades repercutem no ambiente concorrencial em relação às pequenas empresas que operam no mercado tecnológico. Há uma extrema dificuldade em sua manutenção no mercado porque não conseguem concorrer com as grandes empresas, não necessariamente pela falta de conhecimento técnico, mas, às vezes, por falta de recursos para discutir administrativamente ou judicialmente questões concorrenciais, fato que se agrava ainda mais quando as ações são propostas no exterior (CZELUSNIAK; RIBEIRO, 2013).

\section{Procedimento metodológico}

Além das considerações de ordem teórica, que abarcam a revisão de literatura e que sustentam o estudo, optou-se por uma análise empírica que reúne estudo de caso e surveys. Um estudo de caso tem por objetivo "a análise aprofundada de algum, ou alguns (não muitos) casos reais" (YEUNG, 2016, p. 136) e o survey, estudo baseado em entrevista e/ou resposta a questionário, com apresentação de resultados de maneira qualitativa (YEUNG, 2016, p. 135).

No estudo de caso foi analisado um modelo de contrato de transferência de tecnologia firmado entre uma universidade estadual paranaense e uma empresa privada da área metal-mecânica organizada como sociedade limitada, com sede no Paraná, com o objetivo de compreender, explorar e descrever como foi forjado e os principais elementos nos quais as partes se ativeram ao elaborá-lo. Apesar de não poder extrapolar para outros indivíduos a metodologia escolhida, tem o potencial de fornecer insights para futuras pesquisas (GIL, 2002; YIN, 2002).

Dois atores representando cada uma das organizações (empresa e universidade) foram entrevistados por cerca de uma hora cada um entre os dias 20 e 28 de agosto de 2015.

As técnicas de pesquisa desenvolvidas no estudo tiveram dois momentos. No primeiro elaborou-se uma pesquisa documental, para, em seguida, serem desenvolvidas as entrevistas com os dois atores signatário do contrato.

A pesquisa documental detalhou o modelo contratual de transferência de tecnologia, que seguiu o roteiro: (i) leitura dos critérios estabelecidos nas cláusulas; (ii) levantamento dos pontos relevantes a serem analisados; (iii) cotejo entre as condições contratuais e os fatores indutores da cooperação. Ela foi relevante por proporcionar uma série de questionamentos, que foram explorados pelos pesquisadores nas entrevistas com os respondentes.

Nessa etapa, o documento foi tratado e segmentado para análise. Assim, o contrato foi fragmentado em quatro partes: (1) caracterização do contrato; (2) cláusulas de indução à cooperação; (3) existência de mecanismos de ajustes contratuais ou de cláusula de solução de controvérsias; e (4) potencialidade de litígio (a partir da análise da qualidade das cláusulas contratuais em termos de clareza e equidade).

Antes das entrevistas com as partes que celebraram o contrato, foi desenvolvido um roteiro de entrevista não estruturada que teve como base a pesquisa documental. 
As entrevistas foram marcadas com antecedência via contato telefônico. No dia combinado, o pesquisador se dirigiu à empresa. O respondente foi o sócio-proprietário da empresa. Neste período, foram explorados os seguintes tópicos: (1) pretensão de renovação da contratação durante as tratativas que antecederam a negociação; (2) preocupação relativamente às potenciais situações de litígio durante a vigência do contrato; (3) interferência de técnicos ou de advogados na elaboração do contrato; (4) existência de conhecimento ou experiência prévia de contratação; (5) conhecimento das partes em relação às técnicas e elementos de cooperação (cursos, experiência); (6) perspectiva de repetição de negociações (novos contratos) nas mesmas bases do contratado; (7) como foi estabelecida a forma de gestão administrativa e financeira do contrato e se as condições estabelecidas geraram incerteza ou litígio; (8) se as informações necessárias foram satisfatoriamente repassadas pelas partes e se foram realizados outros contratos de prestação de serviço entre as partes para fins de complementação das informações; (9) se as partes consideram que os recursos necessários de parte a parte foram devidamente aplicados para a realização do objeto do contrato; (10) existência de alguma comunicação de parte da cessionária sobre a possibilidade de aperfeiçoamento do produto, qual foi o resultado da comunicação e a divisão de custo.

Na sequência foi entrevistado o docente da universidade, responsável pelo projeto, cujo conteúdo abarcado no roteiro de entrevista foi o mesmo aplicado ao empresário.

\section{Análise de CASO: Discussões e resultado}

O modelo contratual analisado regulamenta uma parceria entre uma Instituição de Ciência e Tecnologia e uma empresa metal-mecânica produtora de tecnologia em bioenergia com vistas à purificação de biogás.

\section{I Caracterização do contrato}

Trata-se de um CTT para outorga de direito de uso/exploração comercial, sem exclusividade de produto tecnológico. O contrato descreve como produto tecnológico o resultado da atividade intelectual no âmbito da universidade na forma de um método, processo e tecnologia alternativa para a purificação de biogás proveniente da biodigestão anaeróbica da matéria orgânica de origem rural, urbana e industrial com dispositivo de troca térmica para pré-aquecimento de comburente.

O contrato informa que a fase de desenvolvimento do produto tecnológico foi encerrada no âmbito da universidade e que a produção industrial e exploração comercial se dará pela empresa. Define o que considera fase de desenvolvimento, de produção e comercialização. A cedente se declara titular dos direitos de propriedade intelectual sobre o produto tecnológico. Cada uma das partes contratantes identificou expressamente a(s) pessoa(s) responsáveis pela execução do contrato. O prazo de duração do contrato foi estabelecido em dois anos, e a possibilidade de prorrogação, prevista expressamente. 


\subsection{Cláusulas de indução À COOPERAÇÃo}

Conforme descrito anteriormente, Axelrod (2010) prevê alguns fatores associados à cooperação, dos quais agora se destacam: (i) a visão de futuro relativamente ao negócio em que a perspectiva de ganho para o futuro supere a lucratividade imediata; (ii) o desmembramento das ações de forma a facilitar a cooperação; (iii) os diferenciais de recompensa se diante de uma atitude de cooperação ou de não cooperação; (iv) a reciprocidade; (v) o reconhecimento de operações passadas; e (vi) a educação para a cooperação.

O modelo contratual estabelece que as partes se comprometam a fornecer as informações necessárias para a viabilidade da produção, a comercialização e o controle do fluxo financeiro, o compromisso de sigilo e a confidencialidade. Determina à cedente e à cessionária envidarem os melhores esforços para a concretização dos objetivos contratuais, assim como fornecer informações relativas ao produto tecnológico.

Prevê que a parte cessionária poderá solicitar à cedente consultoria para apoio técnico e científico relacionado ao objeto do contrato, mediante contratação de prestação de serviço. Relativamente à cedente, prevê a potencialidade de que sejam firmados novos acordos que conduzirão a novos contratos de prestação de serviços para fins de consultoria de apoio técnico e científico na utilização da tecnologia desenvolvida pela cedente. Determina que a cessionária tem o direito de obter, se necessário, o apoio necessário de parte da cedente. $\mathrm{O}$ contrato estabelece apenas sanções gerais para o descumprimento contratual, nesta hipótese.

Nesse sentido, identifica-se no modelo analisado uma previsão acerca da possibilidade de que serviços não descritos expressamente no contrato possam ser solicitados à cedente e que estes serão objeto de acordo em separado.

Prevê que a cessionária realizará os investimentos necessários para a produção e comercialização do produto tecnológico e entregará relatórios financeiros. A remuneração dos contratantes será associada à comercialização dos bens produzidos a partir da tecnologia repassada por meio do contrato.

Estabelece mecanismos de controle em benefício do concedente para que este possa acompanhar o volume de negociação que repercutirá no cálculo de sua remuneração. $\mathrm{O}$ cedente pode realizar a qualquer tempo auditoria independente para controle sobre o cumprimento das obrigações assumidas pela cessionária.

Estabelece que, na hipótese de divergência na análise dos relatórios comerciais da concessionária, será realizada uma perícia técnica cujos custos serão partilhados entre as partes.

O prazo estabelecido para a vigência do contrato é de dois anos, com possibilidade de prorrogação.

Determina a comunicação, de parte da concessionária para com a cedente, quanto à possibilidade de aperfeiçoamento do produto. Na mesma cláusula que dispõe sobre os deveres da concessionária, há uma norma que prevê a obtenção de autorização prévia e formal da cedente para a efetivação de modificação ou ajuste. Outro item da mesma cláusula 
expressamente determina que recairão no concessionário os custos de transporte, estadia e alimentação do pesquisador e equipe técnica quando este(s) for(em) solicitado(s) para trabalho de consultoria técnica in situ.

$\mathrm{O}$ contrato assegura que os direitos de propriedade intelectual que venham a surgir em virtude do contrato serão compartilhados entre as partes e objeto de um termo aditivo.

O contrato é acompanhado de um termo de confidencialidade firmado pela empresa em benefício da universidade. O signatário se compromete a não divulgar os resultados das pesquisas, assim como a não usar ou permitir a outrem que utilize o resultado da atividade intelectual gerada pela universidade sem o seu consentimento. No que se refere à sanção pelo descumprimento, o documento remete genericamente aos potenciais efeitos de ordem civil, penal e administrativa.

\subsection{Conclusões Parciais}

Quanto à existência de cláusulas que induzem à cooperação, o contrato abre uma possibilidade de novas negociações entre as partes, de interesse da cessionária e da cedente, já que consagra a potencialidade de que sejam firmados novos acordos que conduzirão a novos contratos de prestação de serviços para fins de consultoria de apoio técnico e científico na utilização da tecnologia desenvolvida pela cedente. Por outro lado, ao determinar que a cessionária tem o direito de obter, se necessário, o apoio necessário diante da assimetria de informação entre as partes, permite que a cessionária tenha a segurança de contar com o devido apoio técnico. A previsão da possibilidade de que serviços não descritos expressamente no contrato possam ser solicitados à cedente e que estes serão objeto de acordo em separado, demonstra uma opção pelo desmembramento que auxilia no fechamento dos termos do contrato principal, evitando-se que este se torne extenso ou custoso em sua tarefa de disciplina de todas as circunstâncias que possam estar associadas ao negócio.

Como a remuneração dos contratantes é associada à comercialização dos bens produzidos a partir da tecnologia repassada por meio do contrato, a perspectiva de preservação ou de renovação do contrato é um indutor do comportamento cooperativo, uma que a visão de futuro supera os benefícios associados a uma ruptura ou encerramento contratual. Ao atribuir a mesma forma de comprometimento a ambos os contratantes, o contrato prestigia o princípio da reciprocidade. Um fator a ser considerado nos contratos que envolvem transferência de tecnologia é a necessidade de se operar com instrumentos ágeis e eficientes, já que a natureza dos bens negociados se presta a um rápido processo de obsolescência.

No que se refere à divergência na análise dos relatórios comerciais da concessionária e à realização de uma perícia técnica cujos custos serão partilhados entre as partes, a previsão de divisão dos custos, neste caso, pode funcionar como elemento de desestimulo às condutas abusivas, já que aquele que apresenta os relatórios (cessionário) dos negócios saberá de antemão que, no caso de discordância do cedente, será obrigado a partilhar os custos de realização da perícia, o que pode induzi-lo a agir com correção na elaboração dos 
relatórios. O cedente, por outro lado, também levará em consideração, ao ponderar sobre a realização do trabalho técnico, a incidência de custos, evitando-se exigências injustificáveis da parte do agente que detém o poder de exercer atividades de controle.

Sobre a possibilidade de prorrogação do contrato, já estabelecida em seus termos, funciona como instrumento de indução à cooperação, já que a duração do contrato neste modelo (dois anos) é menos relevante do que a perspectiva de futuro decorrente de outras previsões, como a de realização de aditivos de interesse de ambas as partes ou novos contratos e potencialidades de ganhos adicionais voltados ao futuro para ambos. A perspectiva de futuras contratações é corroborada pelas respostas dadas à entrevista.

A previsão do contrato de que os direitos de propriedade intelectual que venham a surgir em virtude do contrato serão compartilhados entre as partes e objeto de um termo aditivo tende a estimular a busca da inovação, mediante promessa de partilha dos resultados. O fato de remeter a disciplina dos novos direitos surgidos a um termo aditivo, mais uma vez revela a disposição em se admitir um contrato incompleto que remete à disciplina de direitos relacionados a novos acordos, cujo teor será elaborado em momento futuro, caso ocorra sua necessidade.

No que se refere à sanção pelo descumprimento do termo de confidencialidade, a previsão de sanções gerais não representa a escolha mais eficiente, já que a previsão mais rigorosa de sanções pelo descumprimento tenderia a ser um instrumento mais adequado para a coibição da conduta indesejada. Todavia, conforme apontado nas entrevistas realizadas, o ambiente de absoluta cooperação estabelecido entre as partes foi suficiente para manter a conduta da empresa em conformidade com os melhores interesses da universidade.

Por fim, sobre os diferenciais de recompensa em relação a atitudes de cooperação ou de não cooperação, pode-se concluir que a prorrogação do prazo do contrato se confirma como recompensa pela adequada performance do concessionário. A propósito do reconhecimento da reputação das partes e da educação para a cooperação, as entrevistas destacam que o contrato analisado somente foi possível em razão de tais elementos.

Vistas as cláusulas que mais se aproximam do instrumental de cooperação trazido por Axelrod (2010), cabe analisar a existência de mecanismos de ajuste do contrato.

\subsection{EXISTÊNCIA DE MECANismos de AJUSTES CONTRATUAis OU DE CLÁUSUla de SOlUÇÃo DE CONTROVÉRSIAS}

$\mathrm{Na}$ hipótese do surgimento de litígios quanto à titularidade dos direitos negociados, o contrato determina que as estratégias sejam decididas de comum acordo. O contrato identifica a hipótese de que os preços de comercialização tomados como parâmetro para a fixação da remuneração do concedente possam sujeitar-se a modificações com base no valor de mercado dos bens e abre a possibilidade dos preços serem reajustados durante a vigência do contrato. A cláusula, na sequência, quantifica o valor estimado para os referidos bens.

Há a previsão do foro judicial da comarca da sede da universidade e não há cláusula arbitral. 


\section{4·3 - i Conclusões parciais}

Com relação à possibilidade de ajustes contratuais, o contrato estabelece diferenciais de recompensa em relação a atitudes de cooperação ou de não cooperação. A já mencionada possibilidade de prorrogação do prazo do contrato se confirma como recompensa pela adequada performance do concessionário.

\subsection{Potencialidade de litígio}

A potencialidade de litígio é tomada neste artigo pela configuração de cláusulas contratuais mal redigidas ou excessivamente abertas.

O contrato estabelece a hipótese de rescisão de pleno direito por acordo entre as partes, bastando uma comunicação com antecedência de sessenta dias, prevê ainda a rescisão por infração ao contrato, desde que tenha sido dada a possibilidade de correção ou justificativa para a outra parte. A falência, recuperação ou liquidação da cessionária também são causas de rescisão.

Por outro lado, o contrato prevê que a concessionária pode rescindir o contrato sem outra formalidade ou exigência, na hipótese de inviabilidade técnica ou econômica do produto ou patente objeto do contrato. Já a cedente tem assegurado o direito de recebimento de royalties com base na média mensal de produtos comercializados, caso a concessionária deixe de cumprir as obrigações assumidas com a cessação da exploração comercial da tecnologia. O contrato estabelece condição de não exclusividade na cessão da tecnologia desenvolvida pela universidade e é omisso quanto à exclusividade de parte da empresa.

Há cláusulas que estabelecem que a universidade tem a gestão administrativa e financeira dos recursos decorrentes do contrato e que a empresa tem a gestão administrativa e financeira dos recursos decorrentes da produção, comercialização do produto tecnológico, objeto do contrato.

O contrato refere-se à oferta por parte da cedente de inovações que possam ser de interesse do cessionário, cujo aperfeiçoamento também fica condicionado à elaboração de um termo aditivo.

\section{4. i Conclusões parciais}

As características do negócio envolvido na cessão de tecnologia recomendam que a extensão do direito das partes seja especialmente bem definida no contrato. Por outro lado, como o contrato prevê a transferência de conhecimento (denominado de produto tecnológico) desenvolvido na universidade e a ser comercializado pela empresa, faz por surgir a situação já comentada neste estudo de que o repasse da tecnologia desenvolvida acarretará o acesso a um conhecimento que não poderá, ao final da vigência do contrato, ser retirado do cessionário. Este somente poderá ser impedido de continuar produzindo e comercializando o bem por força da existência do contrato assinado e do risco de aplicação de sanções, o que confirma a essencialidade do contrato para o negócio, assim como justifica a busca pela redação mais compatível com o objetivo das partes. 
Observa-se que o contrato, ao estabelecer o seu objeto, faz referência a "produto tecnológico”, mas, em uma cláusula, usa a locução "pacote tecnológico”. Como o modelo define apenas produto tecnológico, a existência de outra expressão gera uma potencial fonte de litígio, caso seja do interesse de uma delas a busca de uma interpretação no sentido de que as duas locuções têm significados diferentes, com a produção de diferentes expectativas.

Por outro lado, ao estabelecer condição de não exclusividade na cessão da tecnologia permite à universidade operar com outros parceiros para a exploração do mesmo produto tecnológico. A omissão relativamente à exclusividade de parte da empresa permite concluir que esta pode livremente contratar de forma a obter outros produtos tecnológicos para a produção e comercialização de outros produtos, inclusive no mesmo ramo do produto tecnológico contratado. Esta conclusão pode ser considerada uma potencial fonte de litigiosidade, diante da omissão do contrato.

O contrato tem por objeto a transferência de tecnologia com fins de produção e comercialização dos bens produzidos a partir da aplicação da tecnologia desenvolvida pela universidade. Contém cláusula que estabelece a competência de gestão administrativa e financeira dos recursos (genericamente considerados) decorrentes do contrato, logo, da cessão da tecnologia, para a universidade, ao passo em que estabelece a competência administrativa e financeira dos recursos decorrentes da produção e comercialização do produto tecnológico à empresa. Ao mesmo tempo, a remuneração das partes é fixada em percentuais sobre a venda dos bens produzidos com base na tecnologia repassada. Como é prevista a competência geral de gestão dos recursos decorrentes do contrato para a universidade, seria possível concluir que estes englobariam os recursos cuja gestão é reservada à empresa, pois estes também decorrem do contrato. Todavia, a entrevista realizada revelou que as partes não consideram, até o estágio atual de execução do contrato (cujo equipamento está em vias de ser comercializado) que haja algum equívoco redacional, pois, no seu entendimento, com relação à partilha da gestão, o pesquisador disse que não há incongruência no item apresentado, já que a universidade faz a gestão da parte que lhe compete e o empresário cuida das demais atividades de campo e empresarial.

Por fim, a indeterminação quanto à responsabilidade pelos custos na eventualidade de surgir a possibilidade de aperfeiçoamento do produto, numa sistemática em que os demais potenciais custos são expressamente direcionados, é uma fonte potencial de litígio. A omissão pode, a depender do ambiente negocial resultar numa discussão conduzida por uma autoridade (juiz ou árbitro) ou propiciar um novo ajuste entre as partes. Nessa segunda hipótese, podem os contratantes, por exemplo, decidir sobre a alocação dos custos adicionais da melhor forma para as partes, alternativa cujo sucesso depende da existência de um ambiente cooperativo.

\subsection{Análise geral do resultado das entrevistas}

A entrevista, a partir das questões formuladas, possibilitou o aditamento de informações que os pesquisadores julgaram auxiliares à elaboração das conclusões. 
Das entrevistas se pode extrair que, além dos aspectos explorados nos itens acima relativos aos pressupostos para a cooperação, a reputação foi o fator de aproximação entre a empresa e a universidade, a qual deveu-se a dois fatores. O primeiro foi a rede de relacionamento pré-existente entre o empresário e os docentes da universidade. Essa rede foi reforçada pela aproximação propiciada pelas atividades coordenadas pela associação empresarial do município. No âmbito da associação, tanto empresários como pesquisadores compartilham problemas e carências. Os pesquisadores das universidades têm a oportunidade de comentar com outros pesquisadores de áreas afins as expectativas e as necessidades empresariais locais. A partir dessa aproximação, surgem as possibilidades de que sejam firmados os contratos de desenvolvimento de tecnologia conjuntamente. O segundo fator mais estratégico e que tem por resultado a atração de parcerias é a divulgação das atividades da universidade em feiras, palestras e eventos de divulgação do desenvolvimento de pesquisa e inovação que proporcionam uma ligação entre universidade e empresa. O modelo contratual analisado foi fruto destas duas ações.

O fator reciprocidade é nítido na necessidade de cada uma das partes, uma vez que o pesquisador-líder tinha dificuldades em encontrar alguma empresa que se interessasse pela comercialização do seu produto e o empresário não trabalhava com a purificação do gás, restringindo sua atividade à produção e comercialização de produtos relacionados à resistência do motor em decorrência do desgaste proporcionado pelo gás sulfídrico existente no biogás. O filtro desenvolvido pela universidade veio a solucionar o problema relacionado à purificação do combustível.

Com relação ao fator perspectiva para o futuro, as partes confirmaram seu interesse na perpetuação do relacionamento empresarial. O empresário informou que o bem no atual momento encontra-se praticamente pronto para ser comercializado, após um processo de maturação que se iniciou posteriormente à assinatura do contrato. O protótipo do equipamento derivado da pesquisa realizada na universidade apresentava a necessidade de uma série de ajustes que foram sendo realizados por quase 34 meses.

O pesquisador que representa a universidade reforçou seu interesse na continuação da parceria, pois o recebimento de royalties poderá ocorrer efetivamente nos próximos meses. O prazo inicial do contrato já foi ampliado por termo aditivo, podendo ser renovado até o prazo de 15 anos, quando então estará se aproximando o decurso do prazo de exclusividade sobre a propriedade industrial e a tecnologia passa para a domínio público. Ambas as partes se consideram cooperativas e não houve em momento algum uma preocupação com eventuais litígios entre os contratantes, o que é reforçado pelo fato do empresário ter sido aluno do programa de mestrado da universidade e conhecer os meandros do ambiente acadêmico.

O fator reputação também pode ser identificado no fato de que o empresário e o pesquisador já compartilhavam um bom relacionamento antes do contrato ter sido assinado. Afirmam que se o bom relacionamento não fosse consolidado, as partes não teriam concluído a negociação que conduziu ao contrato. A redação final do contrato decorreu de rodadas 
de negociação, estratégia que minimizou as ações oportunistas pelo relacionamento frequente e a reputação que ambas as partes ostentam.

A minuta básica do contrato foi elaborada pelo pesquisador, que passou para o empresário, que a ajustou às suas necessidades. O empresário afirmou que o modelo não foi analisado de forma específica por nenhum advogado ou outro pessoal técnico. Quando do modelo final, este foi revisado pelos advogados da universidade que quase não interferiram no documento. De acordo com o pesquisador, a preservação da minuta consensual criada pelas partes foi um fator de sucesso do contrato.

Ambas as partes têm interesse na repetição do contrato, consideram que houve avanço significativo de relacionamento, de forma que a parceria está bem sedimentada. O fator aprendizagem também é destacado, pois os entrevistados afirmam que de ambos os lados houve ganhos de conhecimento a partir do processo.

O pesquisador, quando solicitado, tem rapidamente atendido as demandas do empresário, assim como o empresário tem feito investimentos para que a tecnologia desenvolvida atinja condições de comercialização. Os custos em novos investimentos têm sido arcados pelo empresário e a universidade remunera o bolsista que está ajudando na elaboração do manual do equipamento.

\section{CONCLUSÃo}

A opção deste trabalho pelo estudo de caso de um modelo contratual permitiu o cotejo entre uma situação concreta e os pressupostos teóricos propostos, ressaltando, portanto, mecanismos jurídicos e econômicos voltados à elaboração de contratos de transferência de tecnologia mais eficientes.

No campo jurídico, observou-se que o marco teórico da análise econômica do Direito propõe soluções de impasses para além da tutela pela via judicial. O Direito posto pelo Estado é importante, na medida em que traz segurança jurídica para as partes, estabelecendo os direitos de propriedade e os direitos obrigacionais. Contudo, pelo estímulo ao exercício de atitudes cooperativas, as próprias partes podem ser conduzidas ao cumprimento espontâneo das obrigações que lhes sejam cabíveis, o que tem a potencialidade de diminuir os custos das transações. Além disso, a ação cooperativa pode fomentar transações futuras, garantindo novos negócios, e, portanto, nova geração de riqueza.

No campo econômico, o estudo de caso corroborou as hipóteses teóricas levantadas no início do artigo ao demonstrar que a cooperação entre as partes contratantes é um elemento importante, notadamente para os contratos que envolvam transferência de tecnologia - em razão de suas particularidades - como demonstrado no decorrer do estudo. São contratos normalmente complexos que tem como objeto da contratação bens intelectuais, cujo pleno conhecimento não costuma ser transferido ao receptor, já que a assimetria informacional decorre da natureza do bem negociado e dos direitos que se quer proteger. As características 
do objeto negociado favorecem o oportunismo e geram insegurança.

A reputação e a relação existente entre os contratantes influem decisivamente na negociação, tanto no que se refere ao aspecto ex ante, quanto na consecução dos objetivos identificados no documento. A experiência demonstra a potencialidade da reputação como fator de diminuição dos custos de transação. Quanto maior a estabilidade nas parcerias, melhor o ambiente negocial indispensável às economias desenvolvidas.

Por outro lado, o estudo de caso comprova que os elementos que estimulam a cooperação estão presentes no teor do modelo contratual analisado, o que é especialmente relevante em CTTs. Acrescente-se que algumas soluções podem ser destacadas de forma a estimular a cooperação entre as partes para a efetividade dos contratos empresariais de transferência de tecnologia, uma vez que a perspectiva de prolongamento da relação negocial, as estratégias de reciprocidade, o ambiente de boa reputação das partes e a existência de cláusulas abertas a ajustes contratuais corroboram para a eficiência contratual, com a potencialidade de mitigar-se litígios.

O produto tecnológico desenvolvido pela universidade sujeitou-se a aprimoramentos antecedentes à comercialização do equipamento final, aperfeiçoamentos estes que foram implementados de forma consensual. Observe-se, ainda, para que melhor se compreenda os limites da própria conclusão deste estudo, que as partes ainda estão numa fase antecedente à comercialização e partilha dos resultados.

Acredita-se que a ideia apresentada neste artigo possa ser aprimorada em outros estudos que permitam identificar se os contratos de transferência de tecnologia em outros campos da atividade econômica costumam utilizar cláusulas contratuais compatíveis com os pressupostos deste trabalho e qual o grau de eficiência destes contratos, tarefa que pode muito bem ser encampada por equipes multidisciplinares compostas por economistas e juristas. Sugere-se ainda que sejam pensados mecanismos de aferição do papel das estruturas que estimulam a cooperação como fator de redução de custos, tarefa esta que se enquadraria no objeto de estudo de economistas.

\section{REFERÊNCIAS}

ARAÚJO, Fernando. Teoria econômica do contrato. Coimbra: Almedina. 2007.

ASSAFIM, João Marcelo de Lima. A transferência de tecnologia no Brasil. Aspectos contratuais e concorrenciais da propriedade industrial. Rio de Janeiro: Lumen Juris, 2005. 
AXELROD, Robert. A evolução da cooperação. Tradução de Jusella Santos. São Paulo: Leopardo, 2010.

COASE, Ronald. O problema do custo social. Tradução de Francisco Kümmel F. Alves e Renato Vieira Caovilla. Journal of Law and Economics. out. de 1960.

COOTER, Robert; ULEN, Thomas. Direito \& Economia. 5. ed. Tradução de Luiz Marcos Sander e Francisco Araújo da Costa. Porto Alegre: Bookman, 2010.

CORRÊA, Daniel Rocha. Contratos de transferência de tecnologia: controle de práticas abusivas e cláusulas restritivas. Belo Horizonte: Movimento Editorial da Faculdade de Direito da UFMG, 2005.

CZELUSNIAK, Vivian Amaro; RIBEIRO, Marcia Carla Pereira. Cooperação para a efetividade dos contratos de transferência de tecnologia: uma análise juseconômica. Economic Analysis of Law Review, v. 4, n. 1, p. 21-34, jan.-jun. de 2013.

GALLO, Paolo. Contratto e buona fede: buona fede in senso oggetivo e trasformazioni del contratto. Torino: UTET, 2009.

GIL, Antonio Carlos. Como elaborar projetos de pesquisa. São Paulo: Atlas, 2002.

MCDONALD, James; PERRY, Janet; AHEARN, Mary; BANKER, David; CHAMBERS, William; DIMITRI, Carolyn; KEY, Nigel; NELSON, Kenneth; SOUTHARD, Leland. Agriculture economic report no. 837. United States of Department of Agriculture, Washington, nov. 2004. Disponível em <https:/ /www.ers.usda.gov/ webdocs/publications/aer837/14700_aer837_1_.pdf>. Acesso em: 6 jan. 2011.

NANNI, Giovanni Ettore (Org.). Temas relevantes do direito civil contemporâneo: reflexões sobre os cinco anos do Código Civil. Estudos em homenagem ao Professor Renan Lotufo. 1. ed. São Paulo: Max Limonad, 1999.

NORTH, Douglass C. Economic performance through time. The American Economic Review, v. 84, n. 3, p. 359-368, jun. 1994. Disponível em: <http: //www.jstor.org/stable/2118057>. Acesso em: 27 de abr. de 2011.

OECD/Food and Agriculture Organization of the United Nations. OECD-FAO Agricultural Outlook 2015. OECD Publishing: Paris, 2015. Disponível em: <http://dx.doi.org/10.1787/agr_outlook2015-en>. Acesso em: 6 abr. 2017.

PRADO, Maurício Curvelo de Almeida. Contrato internacional de transferência de tecnologia: patente e know-how. Porto Alegre: Livraria do Advogado, 1997. 
RIBEIRO, Marcia Carla Pereira; GALESKI JUNIOR, Irineu. Teoria geral dos contratos: contratos empresariais e análise econômica. 2. ed. São Paulo: Revista dos Tribunais, 2016.

ROCHA JR., Weimar Freire da; BITTENCOURT, Mauricio Vaz Lobo; RIBEIRO, Marcia Carla Pereira. Contratos no agronegócio. Anais ESADR - I Encontro Lusófono em Economia, Sociologia, Ambiente e Desenvolvimento Rural. Évora, 2013.

TIROLE, Jean. Cognition and incomplete contracts. American Economic Review, Pittsburgh, v. 99, n. 1, p. 265-294. mar. 2009.

ZYLBERSZTAJN, Decio; SZTAJN, Rachel. Direito \&economia: análise econômica do direito e das organizações. Rio de Janeiro: Elsevier. 2005.

YEUNG, Luciana. Jurimetria. In: RIBEIRO, Marcia Carla Pereira; DOMINGUES, Victor Hugo; KLEIN, Vinicius (Coords). Análise econômica do Direito: justiça e desenvolvimento. Curitiba: CRV, 2016.

YIN, Robert K. Estudo de caso: planejamento e métodos. Porto Alegre: Bookman, 2002.

WILLIAMSON, Oliver E. The lens of contract: private ordering. American Economic Review, Nashville, v. 92, n. 2, p. 438-433, mai. 2002.

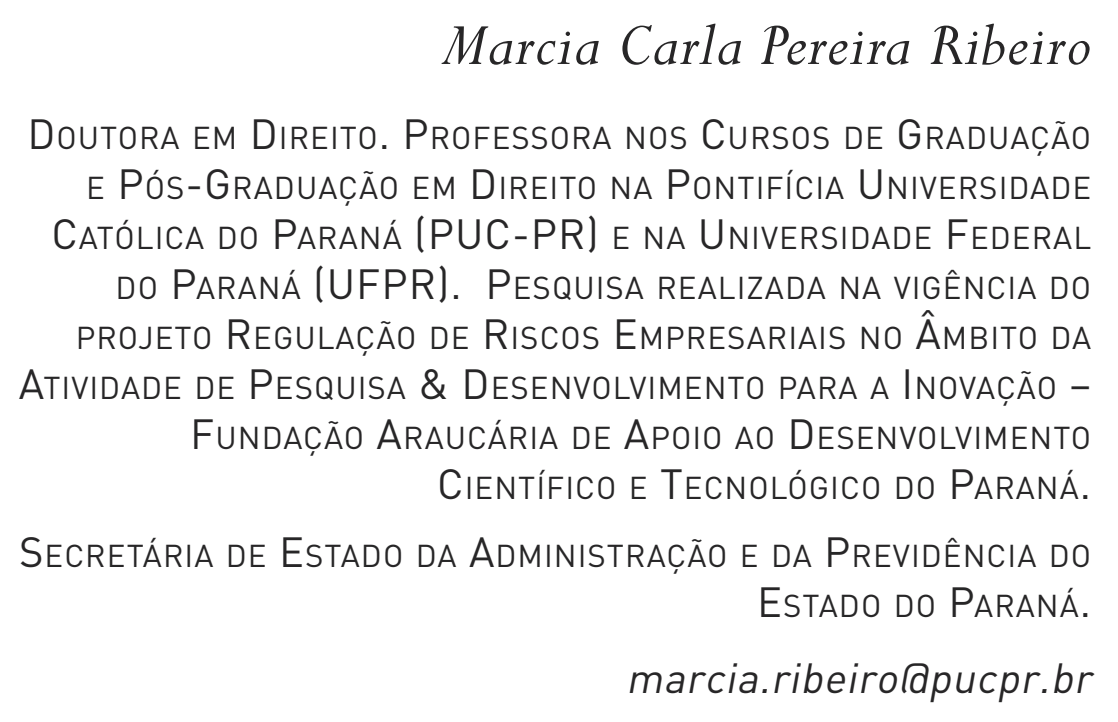


MECANISMOS JURÍDICOS E ECONÔMICOS PARA A TRANSFERÊNCIA DE TECNOLOGIA: UM ESTUDO DE CASO : $6 \mathbf{8}$

Weimar Freire da Rocha Jr.

Coordenador e Professor Doutor do Programa de PósGraduação em Desenvolvimento Regional e Agronegócio e do Curso de Graduação da Universidade Estadual do Oeste do Paraná (Unioeste).

wrochajr2000agmail.com

\section{Vivian Amaro Czelusniak}

Professora colaboradora Doutora do Programa de PósGraduação em Direito - Mestrado do Centro Universitário Autônomo do Brasil (UniBrasil) e Professora no Curso de

Graduação em Direito do Centro Universitário Curitiba (UNICURITIBA).

vivian.amarolgmail.com 